\title{
Hydrogen Underground Storage as a Critical Factor in the Energy Transition Period
}

\author{
Ivan ZELENIKA, Darko PAVLOVIĆ*, Pavo RAJIČ, Tomislav KOVAČIĆ, Melita SRPAK
}

\begin{abstract}
In this paper, the authors elaborated on the conversion of excess electricity, generated from renewable energy sources by water electrolysis, into chemical energy and on its underground storing. Specifically, one of potential solutions in the function of transition and decarbonization of the energy sector is a project of conversion and storage of wind and solar energy, that is, underground storage of chemical energy (hydrogen). In the primary cycle of producing and storing hydrogen, underground storing of hydrogen (UHS) in geological formations is a crucial factor in storing large volumes of energy for a theoretically longer, or an indefinite period. The paper presents possibilities of using the stated technology in Croatia by using a small standard underground gas storage facility (UGS). The article presents technical-technological process of producing and underground storing of hydrogen: from generating electricity through renewable energy sources or other industrial processes generating waste energy, the production of hydrogen and its compression, transport and storage in underground geological formations. In this paper, the authors will also elaborate on the status of the EU States' regulations, which present the main factor for the previously mentioned activities, as well as on the necessary changes that the relevant regulations need to undergo.
\end{abstract}

Keywords: hydrogen production; renewable energy sources; underground hydrogen storage; underground porous geological formation

\section{INTRODUCTION}

A high energy demand may jeopardize energy security. Large energy systems, such as the electric power industry and national gas system, are characterized by a complex structure, which requires a planning approach, selection of a maintenance strategy, and engagement of considerable resources, workforce, and time [1]. For many years energy storage has been marginalized, partly because the current technology was not economically viable, and partly because energy storage was economically less valuable in fossil fuel-dominated energy systems. However, this condition is continuously changing due to the energy storage technology improvement and On-going decarbonisation policy leading to a significant increase in renewable energy sources (RES) as a share of electricity generation. Globally, economic and population growth leads to higher $\mathrm{CO} 2$ emissions derived from fossil fuel combustion and causes climate changes, which are recognized as one of the most important 21 st-century issues [2].

Stochastic renewable energy sources (wind farms and photovoltaic systems) are increasing year by year in EU countries, but still not exceeding the $20 \%$ limit in the total share of the energy produced [3]. Higher levels of the penetration of RES are possible, but not without addressing many technical challenges that result from their intermittent work. In this context, it should be noted that electricity production from RES is highly dependent on the weather, with no possibility of retaining continuous stable electricity production. Managing the electricity grid with a high share of RES is a challenge that could lead to unnecessary energy losses and a disproportion between electricity supply and demand. Consequently, if no energy storage technology is employed, the surplus energy generation will be unutilized. To increase the security of energy supply and to achieve greater efficiency of electrical grid systems with a share of RES, it is necessary to link the energy storage technology with an electrical grid system. Managing the electricity system able to accept large quantities of electricity, produced from intermittent (stochastic) sources, such as wind and solar, is achievable with the implementation of energy storage technology. To meet the demanding decarbonisation objectives, targeted by the European Commission's long-term strategy [3, 4] the power system will have to reach complete carbon neutrality by 2050 . Renewable energy sources, in particular solar and wind power will play the leading role in this transition since their cost should continue to decline over the following decades, and energy storage, obtained from RES, will help in the transition to low carbon-based energy production and utilization. Recent research indicates that hydrogen will play a vital role in the energy distribution, supply and storage chain generated from RES. The current underground gas storage technology (for natural gas) can also be used to economically and safely store hydrogen produced from RES in widely available reservoirs [5]. Excess electricity derived from stochastic RES is used in the electrolysis process to separate water molecules into hydrogen and oxygen. The separated hydrogen is further compressed to the reservoir pressure and stored for later use. Besides, if suitable gas quality standards exist to facilitate direct hydrogen blending, direct injection into the gas system network is also possible. Continuous developing technological solutions of the electrolysis system are crucial to converting the excess electricity from RES into hydrogen. Mentioned can also be seen in the list of current pilot projects related to hydrogen production in EU countries, where out of a total of 33 existing projects, almost half use the electrolysis system. Also, EU countries are currently at the forefront in the development and production of advanced electrolysis systems specifically designed to produce hydrogen from the excess energy generated through RES. Observations from the scientific community involved in hydrogen research predict that hydrogen, as an energy carrier, will achieve commercial sustainability in the coming years, bringing value in achieving the goals set by the Paris Agreement in terms of sustainability and independence of the energy system [6]. We can say that hydrogen is becoming a key part of the more sustainable and secure energy future, with the authors particularly emphasizing the fact that the EU has a developed system for the transmission and distribution of gas across the continent. In order to achieve economic viability, the use of hydrogen 
in the gas transport network should be considered as a sustainable long-term energy option.

\section{STORAGE OF HYDROGEN AND NATURAL GAS IN GEOLOGICAL FORMATIONS - AN EXAMPLE OF TYPICAL GAS STORAGE IN THE REPUBLIC OF CROATIA}

Producers of electricity generated from stochastic RES are usually only partially compensated in case of inability to deliver produced electricity to the grid due to reduced electricity demand or the excess load of the electric system grid. Future legal regulatory frameworks for these issues should be even more rigorous. Along with energy production, the need for energy storage is determined by the imbalance between energy production and consumption. Energy consumption usually fluctuates over time, while energy production is generally constant or randomly intermittent (as in the case of stochastic renewable energy sources). Such large amounts of energy generated by the imbalance between RES production/consumption on a regional level could only be stored in Geological reservoirs in the form of chemical energy (hydrogen). One cubic meter of hydrogen produces 12.7 MJ of energy by combustion [7], which is a very high energy potential, although lower than the one of methane (40 MJ). Being convertible to electricity or heat, hydrogen becomes an efficient energy carrier capable of transporting and storing energy. The transport of energy, in the form of gas, generates considerably less loss $(<0.1 \%)$ than transport by power network $(8 \%)$ [8]. Due to its high energy potential, hydrogen can replace up to $60 \%$ of natural gas used for nonindustrial activities [9]. The storage of hydrogen is thus the storage of energy. Previous studies $[5,10]$, indicate that the geological formations are suitable for storing natural gas and may be used for the storage of non-hydrocarbon gases (hydrogen). There are three basic types of underground gas storage (UGS), considering the type of geological formations in which gas is stored, Fig. 1. Each of these types has different physical and economic characteristics, which determine the suitability of a storage for a given application:

- depleted oil \& gas reservoirs,

- aquifer reservoirs,

- $\quad$ salt cavern reservoirs.

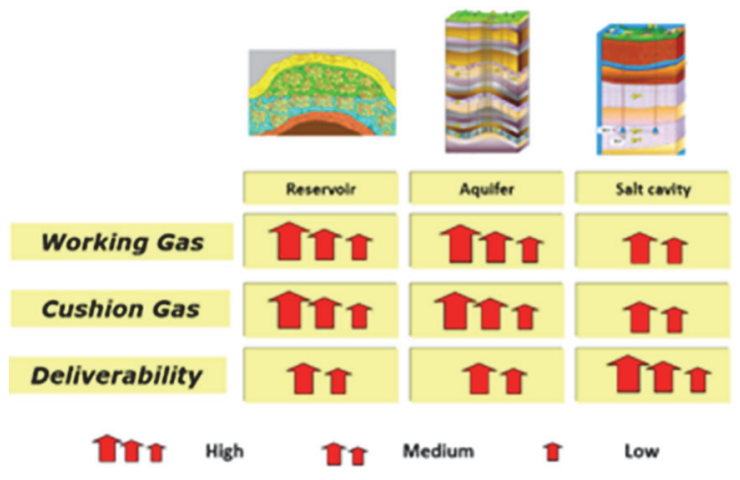

Figure 1 Types of gas storage reservoirs [11, 12]

Gas storage in depleted oil and gas fields is the most common and generally the least expensive method of storing large quantities of natural gas. Depleted reservoirs represent geological formations from which gas reserves have already been depleted, in a certain percentage, and therefore they are assumed appropriate for gas storage.

Aquifer storage is based on the same concept as depleted oil/gas fields; however, it is a more costly option since aquifers require conditioning and more preliminary work to prove their capability to hold and contain gas under pressure. They also need more significant investment in cushion gas since the reservoir formerly held saline waters [13-15]. Underground salt formations (domes) offer another option for natural gas storage. These formations are well suited to natural gas storage, once formed; they allow little injected natural gas to escape from the formation. The walls of a salt cavern also have adequate structural strength, which makes it very resilient against reservoir degradation during the working period of the storage facility.

Developing UGS involves a substantial initial investment, especially the one related to the assessment of storage capacity and retention of an injected gas in the reservoir without the possibility of its migration or loss. Although the hydrogen storage in conventional UGS is the most economical one and so far it has not shown significant negative indicators, due to the specific characteristics of hydrogen (low weight and molecular size, high mobility and reactivity with microorganisms), before starting storage it is necessary to carry out a series of laboratory and reservoir tests to determine the suitability of the site for underground hydrogen storage (UHS). During hydrogen storage, it was found out that a maximum of $2 \%$ of hydrogen is lost due to diffusion through cap rock and a maximum of $2 \%$ due to dissolution in reservoir water [11]. This chapter discusses the concept of long-term storage of hydrogen in a porous geological formation. The process of storing hydrogen in geological formations is technologically like the storage of natural gas. An example of hydrogen production and storage process, in a typical geological gas storage formation in the Republic of Croatia, is shown by Fig. 2 .

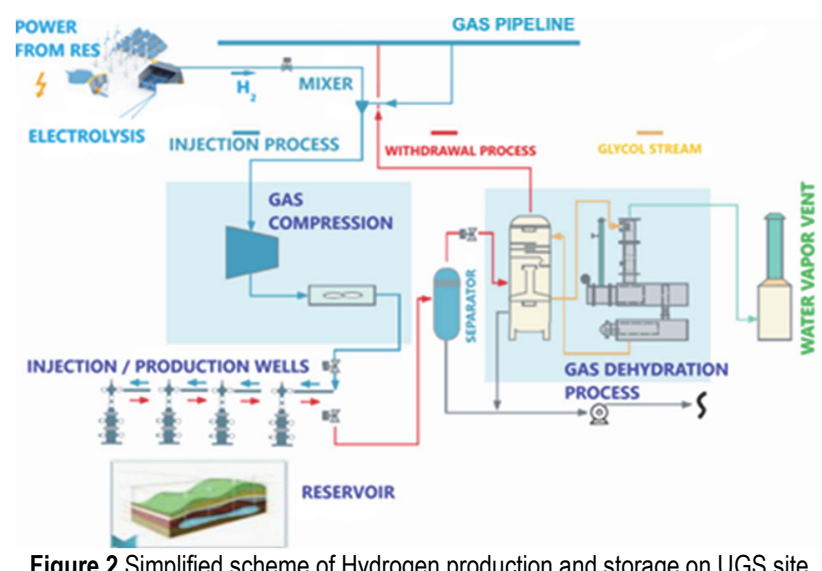

In the above scheme, excess production of electricity from renewable energy sources is used for hydrogen production via the proton exchange membrane (PEM) electrolyser. Water electrolysis is one of the simplest methods used for hydrogen production, and it is justified if the electricity is cheap or obtained from renewable energy sources [16, 17]. The fundamental design of the PEM electrolysis process is shown by Fig. 3, below. 


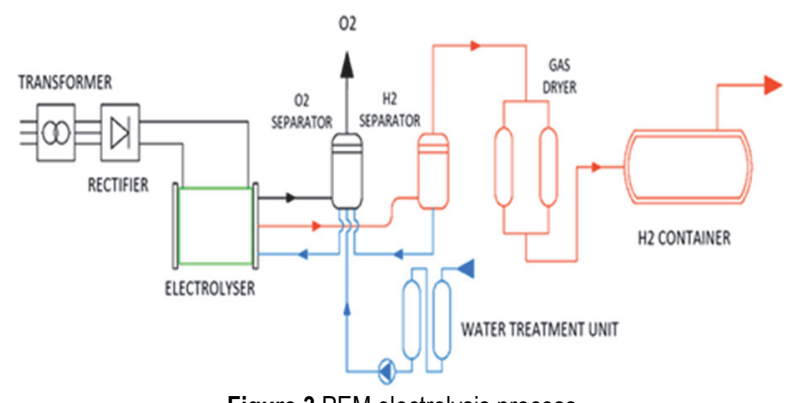

Figure 3 PEM electrolysis process

The components of the PEM electrolyser: a membrane electrode assembly (includes membrane, anode and cathode electrodes), gas diffuser (current collector), gasket, bipolar plates, and interconnector. For PEM electrolysers, the current efficiency (Faraday efficiency) is assumed to be over $99 \%$ [18]. Since the process of hydrogen production is atmospheric, produced hydrogen is collected in a tank located in front of the compressor and then compressed to the required transport pressure. Hydrogen produced by the PEM electrolysis process is very pure gas, saturated with water; the oxygen content does not usually exceed the value of $0.2 \%$. If higher purity is required, remaining oxygen molecules can be removed by a catalytic reaction in a deoxidizer. After compression, hydrogen gas is dried in a desiccant filled with the moisture-absorbing desiccant. Within the electrolysis plant, it is also necessary to provide a chemical preparation of water used in the electrolysis process. It is usually done with membrane filtration or ultra-filtration system. The average requirement for water, used by the electrolysis system, is approximately $0.9-1$ litter of purified water per standard cubic meter of the produced hydrogen [19]. After cooling, produced hydrogen is mixed with natural gas to a certain extent, then measured before entering the compressor units where it is compressed to the reservoir pressure value. After compression, the mixed gas is transported to the injection wells and injected into the geological formation. During the production (withdrawal) cycle, a mixed NG/H2 stream could be injected directly in a gas transport network, or the hydrogen could be separated from NG and converted to electrical energy via fuel cell technology. It should be noted that certain studies $[6,20,21]$, have demonstrated compatibility of the existing gas storage facilities and natural gas transportation infrastructure with hydrogen. Current research and industry practice conclude that the technology used to compress and transport natural gas is suitable for working with a mixture of natural gas and hydrogen (up to $20 \%$ of hydrogen) at high operating pressure.

\subsection{Selection of Simulation Scenarios - Hydrogen/Natural Gas Storage in the Reservoir by Using Electricity Generated via Surplus RES}

Three scenarios of hydrogen storage in a conventional reservoir were considered, depending on the amount of available electricity generated by stochastic RES. Scenario selection and calculation are based on the current and future (estimated) potential of wind farms (RES) in the Republic of Croatia because, by the end of 2017, a total installed capacity of wind power plants was $75 \%$ of the total RES installed capacity in the Republic of Croatia [22].
Total installed wind and solar energy in Croatia by the end of 2017 was $625 \mathrm{MW}$, with wind farms' maximum capacity of $576 \mathrm{MW}[22,23]$. In 2017, $1204 \mathrm{GW}$ of electricity was produced from wind farms, which accounts for $24 \%$ of the total theoretical annual production of $5045 \mathrm{GW}$. Regarding the fact that it is not possible to utilize the total electricity produced by wind farms due to mismatch between the electricity supply and demand, for the purposes of this work, it is assumed that $5 \%$ of the total installed wind farm capacity could be used as non-utilized power for hydrogen production.

Fig. 4 shows the increase in RES in Croatia for the period between 2007 and 2017. According to graph data, a further increase in RES is assumed in the scenario for research purposes for the period of the following 10 and 20 years.

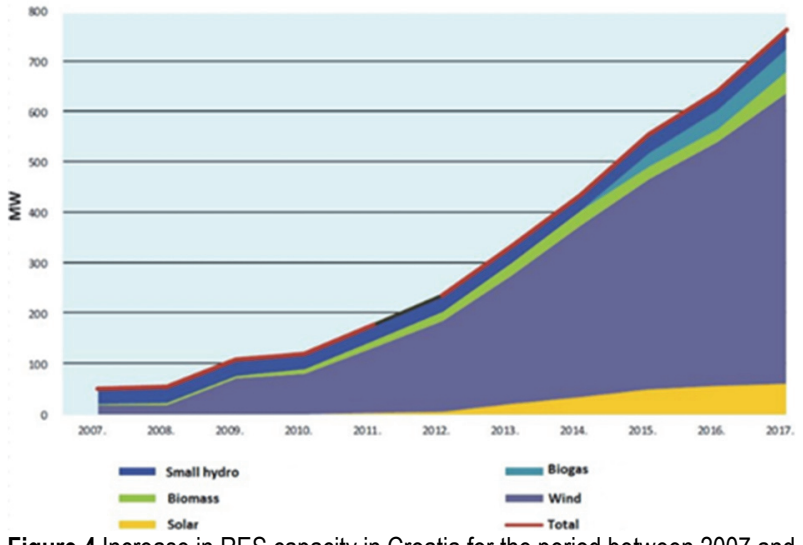

Figure 4 Increase in RES capacity in Croatia for the period between 2007 and 2017 [11]

Input data for electrolyser system sizing are shown in Tab. 1. Modern systems for hydrogen production by electrolysis require 50 to $70 \mathrm{kWh}$ of electricity to produce $1 \mathrm{~kg}$ of purified hydrogen [19].

Table 1 Rated electrolyzer input power for all three scenarios

\begin{tabular}{|c|c|c|}
\hline Time & $\begin{array}{c}\text { Predicted installed } \\
\text { power, MW (WIND) }\end{array}$ & $\begin{array}{c}\text { Input calculation data, MW (5\% } \\
\text { of total installed wind capacity) }\end{array}$ \\
\hline present & 576 & 28 \\
\hline In $10 \mathrm{y}$. & 973 & 48 \\
\hline In $20 \mathrm{y}$. & 1358 & 68 \\
\hline
\end{tabular}

According to technical parameters provided by equipment manufacturer (OEM) and regarding power availability for RES, three scenarios are provided to produce hydrogen, as shown in Tab. 2.

Table 2 Hydrogen production scenarios

\begin{tabular}{|c|c|}
\hline $\begin{array}{c}\text { Input calculation data, MW } \\
\text { (5\% of total installed wind capacity) }\end{array}$ & $\begin{array}{c}\mathrm{H} 2 \text { production, } \mathrm{kg} / \mathrm{h} \\
\text { (PEM electrolyser) }\end{array}$ \\
\hline 28 & 560 \\
\hline 48 & 980 \\
\hline 68 & 1360 \\
\hline
\end{tabular}

\section{SIMULATION RESULTS - STORAGE OF NATURAL GAS AND HYDROGEN IN A POROUS GEOLOGICAL FORMATION}

For this study, a non-existent but realistically characterized underground storage reservoir Alfa (UGS Alfa), is used to simulate natural gas and hydrogen underground storage. All successive natural gas and 
hydrogen underground storage scenarios are developed using a projection of typical fluctuation of renewable energy production, as described in the previous chapter. UGS Alfa was formed in a structural-stratigraphic trap. It is represented with two anticlines separated with a watersaturated structural saddle and consists of two reservoirs: Alpha 1 and Alpha 2. Reservoir boundaries of Alpha 1 and Alpha 2 are defined by the shape of the structure at the top and gas/water contact at the bottom, Figs. 5 and 6 .

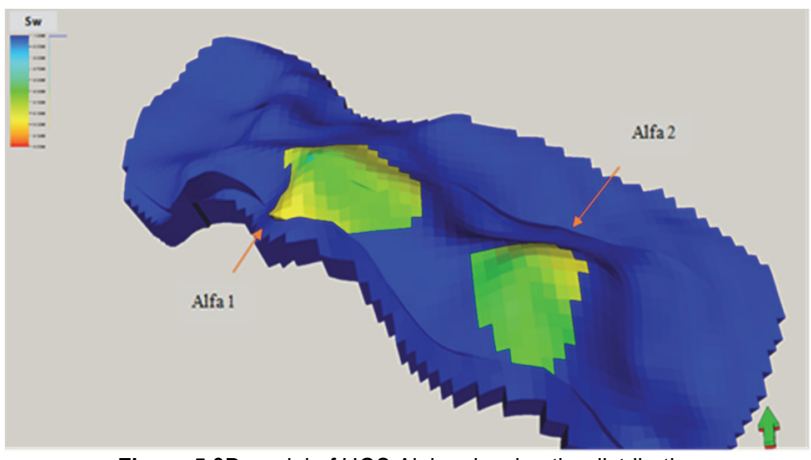

Figure $53 \mathrm{D}$ model of UGS Alpha showing the distribution of initial water saturation

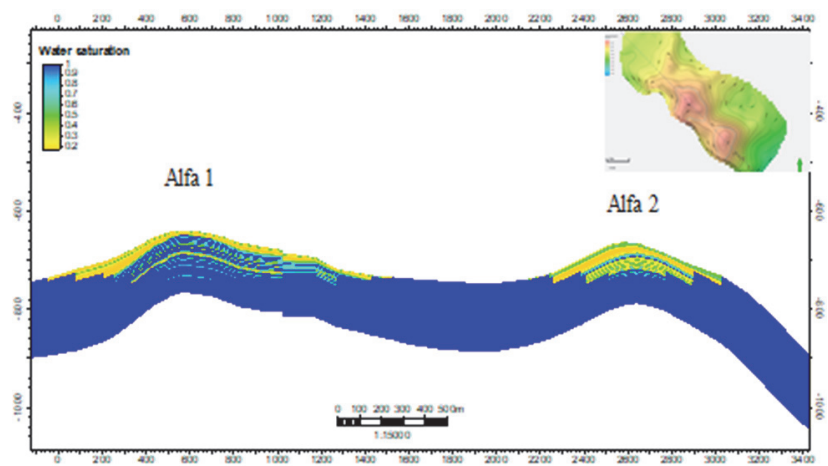

Figure 6 UGS Alfa geological cross-section (Alfa 1 and Alfa 2 reservoirs) showing the distribution of initial water saturation

Reservoirs are represented with metamorphic rocks of the Neogene's basement, chronostratigraphic undefined, and bioclastic limestones and conglomerate sandstones of the Miocene age [15]. Reservoirs are characterized by secondary fractured porosity and very good permeability. Seals are $68 \mathrm{~m}$ thick marls above the Alfa 1 reservoir and 65 thick marls above the Alfa 2 reservoir. UGS Alfa consists of 16 withdrawal/injection wells; seven wells are located at Alfa 1 reservoir and nine wells at Alfa 2 reservoir. Due to the continuous and steady flow of produced hydrogen, the annual (seasonal) storage system in cycles is selected for continuous natural gas and hydrogen withdrawal/injection. The maximum allowable storage pressure of each reservoir is $10 \mathrm{MPa}$ (100 bar).

The minimum storage pressures of the reservoirs in the function of maximizing the withdrawal of injected gases are set to $5.5 \mathrm{MPa}$ (55 bar).

Total Gas in Place (GIP) in reservoir Alfa 1 and Alfa 2 are $679 \times 10^{6} \mathrm{~m}^{3}$ and $321 \times 10^{6} \mathrm{~m}^{3}$, respectively. Accordingly, the working gas volume on the UGS Alfa is $453 \times 10^{6} \mathrm{~m}^{3}$, which is, in the Alfa 1 reservoir, it is $309 \times 10^{6} \mathrm{~m}^{3}$, and in the Alfa 2 reservoir, it is $144 \times 10^{6} \mathrm{~m}^{3}$. Basic technical data assigned to the individual reservoirs are shown in Tab. 3.
Table 3 UGS Alfa basic technical data

\begin{tabular}{|l|c|c|}
\hline \multicolumn{3}{|c|}{ Basic technical data of the facility/reservoirs } \\
\hline Reservoir & Alfa 1 & Alfa 2 \\
\hline Maximum allowable storage pressure / bar & \multicolumn{2}{|c|}{100} \\
\hline Minimum storage pressure / bar & \multicolumn{2}{|c|}{55} \\
\hline Reservoir temperature $/{ }^{\circ} \mathrm{C}$ & \multicolumn{2}{|c|}{65} \\
\hline True vertical depth $(\mathrm{TVDSS}) / \mathrm{m}$ & 705 & 716 \\
\hline Working gas volume $/ 10^{6} \mathrm{~m}^{3}$ & 309 & 144 \\
\hline Cushion gas volume $/ 10^{6} \mathrm{~m}^{3}$ & 370 & 177 \\
\hline Gas in place $(\mathrm{GIP}) / 10^{6} \mathrm{~m}^{3}$ & 679 & 321 \\
\hline Number of wells (withdrawal and injection) & 7 & 9 \\
\hline Nominal withdrawal flow $/ 10^{6} \mathrm{~m}^{3} /$ day & \multicolumn{2}{|c|}{2.5} \\
\hline Withdrawal cycle/Injection cycle & $1.10 .-31.3 . / 1.4-30.9$. \\
\hline
\end{tabular}

Main drive mechanism (energy regime) in the reservoirs is volumetric (compression and expansion of stored gas and cushion gas), influence of aquifer is very small, and it is neglected for the purpose of this study. The UGS Alfa is designed with a maximum withdrawal/ injection capacity of $2.5 \times 10^{6} \mathrm{~m}^{3} /$ day.

Regarding the data inputs based on the selected scenarios, a mixture of natural gas and hydrogen of different molar composition is injected into the reservoir with constant injection capacity. For the first 12 years molar content of hydrogen was $7 \%$, for the next 10 years molar content of hydrogen was $10 \%$ and for the last 10 years of the simulation molar content of hydrogen was set to $16 \%$. The scenario calculations are carried out using the MBAL software from Petroleum Experts Ltd. The gas mixture and properties are calculated using a generalized formulation of the Peng-Robinson equation of state for the gas compositions listed in Tab. 4, a) original reservoir gas b) natural gas blended with $7 \% \mathrm{H}_{2}$, c) natural gas blended with $11 \% \mathrm{H}_{2}$ d) natural gas blended with $16 \% \mathrm{H}_{2}$ ).

Table 4 Gas composition used in the simulations

\begin{tabular}{|c|c|c|c|c|}
\hline \multirow{2}{*}{ Component } & \multicolumn{4}{|c|}{ Composition, mole /\% } \\
\cline { 2 - 5 } & $\mathrm{a})$ & $\mathrm{b})$ & $\mathrm{c})$ & $\mathrm{d})$ \\
\hline $\mathrm{CO}_{2}$ & 0.77 & 0.77 & 0.77 & 0.76 \\
\hline $\mathrm{C}_{1}$ & 97.70 & 90.72 & 86.72 & 81.75 \\
\hline $\mathrm{C}_{2}$ & 0.81 & 0.80 & 0.80 & 0.79 \\
\hline $\mathrm{C}_{3}$ & 0.26 & 0.25 & 0.25 & 0.25 \\
\hline $\mathrm{IC}_{4}$ & 0.23 & 0.23 & 0.23 & 0.23 \\
\hline $\mathrm{NC}_{4}$ & 0.08 & 0.08 & 0.08 & 0.08 \\
\hline $\mathrm{IC}_{5}$ & 0.08 & 0.08 & 0.08 & 0.08 \\
\hline $\mathrm{NC}_{5}$ & 0.02 & 0.02 & 0.02 & 0.02 \\
\hline $\mathrm{C}_{6}$ & 0.05 & 0.05 & 0.05 & 0.05 \\
\hline $\mathrm{H}_{2}$ & - & 7.00 & 11.00 & 16.00 \\
\hline
\end{tabular}

The phase diagrams for these gas compositions are shown by Fig. 7 .
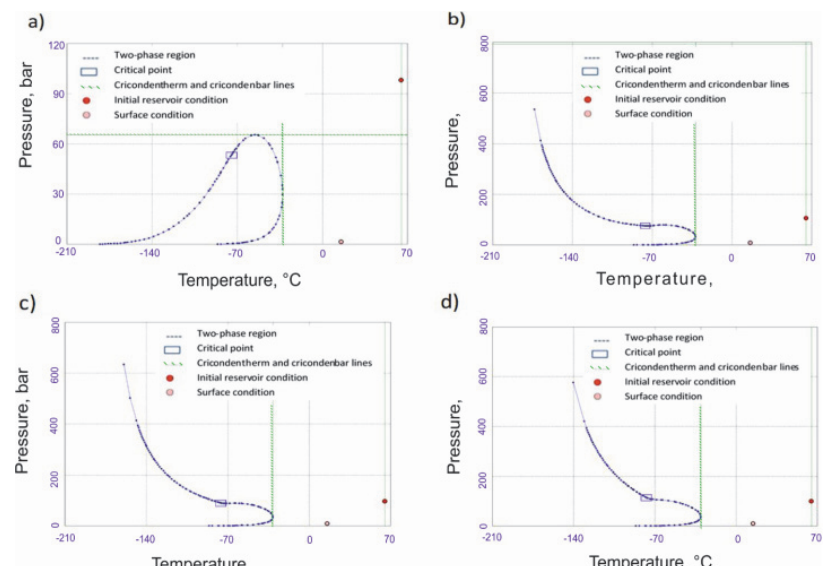

d)

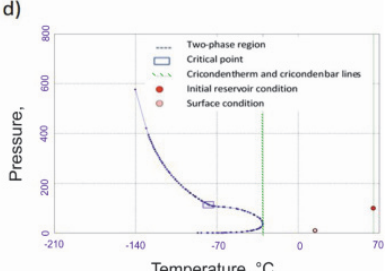

Figure 7 Phase diagram: a) original reservoir gas; b) natural gas blended with $7 \% \mathrm{H}_{2} ;$ c) natural gas blended with $11 \% \mathrm{H}_{2} ;$ d) natural gas blended with $16 \%$ 
Before the first injection cycle, original reservoir gas was produced, and initial reservoir pressure was set to $1 \mathrm{MPa}$ (10 bar). After primary depletion, natural gas with a molar composition of $7 \%$ hydrogen was being injected into Alpha 1 and Alpha 2 reservoirs for two years until initial pressure was reached. Thereafter, as previously stated, the gas of the same composition was stored for ten withdrawal/injection cycles.

Figs. 8 and 9 show the parameters of the UGS Alpha operation during mixed gas injection and withdrawal.

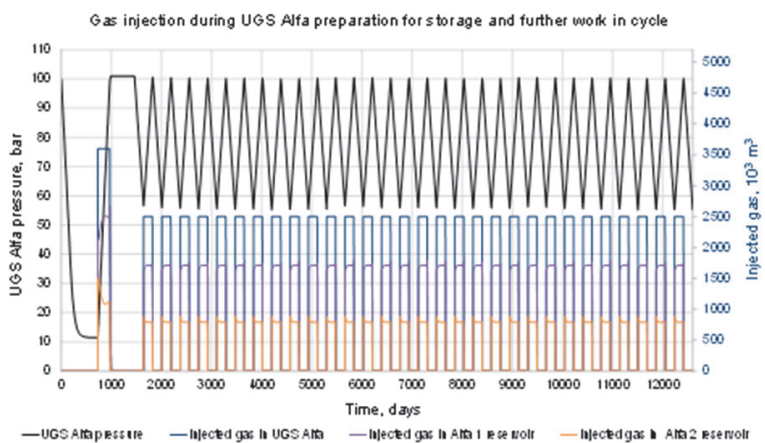

Figure 8 Gas injections during UGS Alfa preparation for storage and further operation by cycle

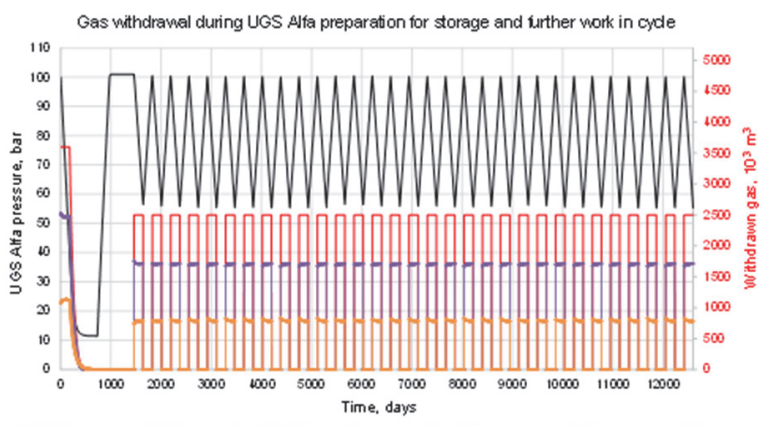

Figure 9 Gas withdrawals during UGS Alfa preparation for storage and further operation by cycle

Fig. 10 shows an increase in the molar content of hydrogen in gas composition during gas storage in Alpha 1 and Alpha 2 reservoirs. After several cycles (resulting in the increase of the molar content of hydrogen in the injected gas mixture), the molar content of hydrogen in reservoirs is equalized with the molar content of hydrogen in the injected gas mixture.

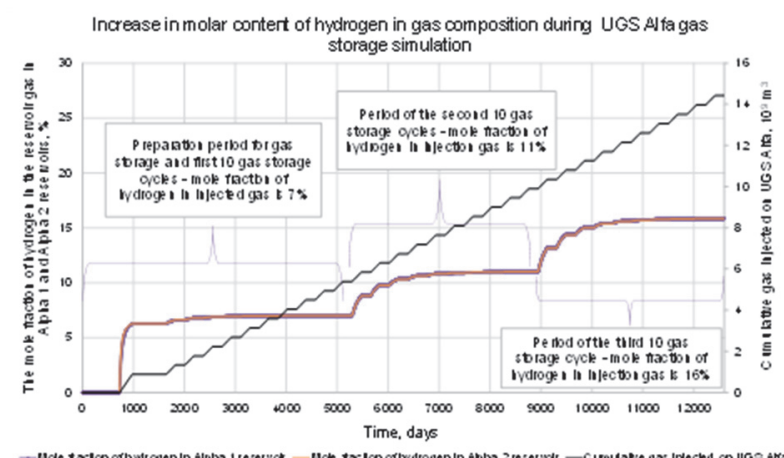

Figure 10 Increase in molar content of hydrogen in gas composition UGS Alfa gas storage simulation

The considered calculations are carried out by an analytical model made in the MBAL software, and the volumetric mixing of the injected and reservoir gas is assumed for each injected cycle. The shown simulation result is within the expected range. Permeability in UGS Alfa reservoirs is very good, and reservoirs are developed with enough wells that are optimally located to fully activate all gas in the reservoirs during the storage operation. Also, an increase in the hydrogen content of gas increases its mobility; it can be considered that the mixing of gas in the reservoir is approximately volumetric and that the modelling results are representative in this case. To model these reservoir processes more accurately, it is necessary to use a compositional 3D numerical reservoir model.

Table 5 Change of natural gas and hydrogen inventory and change in energy balance over time in UGS Alfa

\begin{tabular}{|c|c|c|c|c|c|}
\hline $\begin{array}{c}\text { Time / } \\
\text { Days }\end{array}$ & $\begin{array}{c}\text { Withdrawal } \\
\text { Cycle } \\
\#\end{array}$ & $\begin{array}{c}\text { Stored } \\
\text { hydrogen } \\
\text { volume } \\
/ 10^{3} \mathrm{~m}^{3}\end{array}$ & $\begin{array}{c}\text { Stored } \\
\text { natural gas } \\
\text { volume } \\
/ 10^{3} \mathrm{~m}^{3}\end{array}$ & \begin{tabular}{|c|}
$\begin{array}{c}\text { Stored } \\
\text { hydrogen } \\
\text { energy } \\
/ \mathrm{GW} \cdot \mathrm{h}\end{array}$ \\
\end{tabular} & $\begin{array}{c}\text { Stored } \\
\text { natural gas } \\
\text { energy } \\
/ \mathrm{GW} \cdot \mathrm{h}\end{array}$ \\
\hline 0 & 0 & 0 & 453.07 & 0 & 4383.64 \\
\hline 1.643 & 1 & 28.36 & 424.14 & 81.01 & 4103.81 \\
\hline 2.008 & 2 & 29.87 & 422.63 & 85.34 & 4089.16 \\
\hline 2.373 & 3 & 30.7 & 421.80 & 87.71 & 4081.12 \\
\hline 2.739 & 4 & 31.32 & 423.68 & 89.49 & 4099.29 \\
\hline 3.104 & 5 & 31.40 & 421.11 & 89.69 & 4074.42 \\
\hline 3.469 & 6 & 31.53 & 420.98 & 90.07 & 4073.16 \\
\hline 3.834 & 7 & 31.59 & 420.91 & 90.26 & 4072.48 \\
\hline 4.200 & 8 & 31.81 & 423.19 & 90.87 & 4094.62 \\
\hline 4.565 & 9 & 31.65 & 420.85 & 91.43 & 4071.93 \\
\hline 4.930 & 10 & 31.66 & 420.84 & 91.46 & 4071.82 \\
\hline 5.112 & 11 & 31.68 & 420.83 & 91.49 & 4071.71 \\
\hline 5.477 & 12 & 39.84 & 412.66 & 113.83 & 3992.68 \\
\hline 5.842 & 13 & 44.33 & 408.17 & 126.65 & 3949.25 \\
\hline 6.208 & 14 & 47.06 & 407.94 & 134.45 & 3947.04 \\
\hline 6.573 & 15 & 48.16 & 404.34 & 137.59 & 3912.21 \\
\hline 6.938 & 16 & 48.90 & 403.60 & 139.7 & 3905.07 \\
\hline 7.303 & 17 & 49.30 & 403.20 & 140.84 & 3901.19 \\
\hline 7.669 & 18 & 49.79 & 405.21 & 142.25 & 3920.62 \\
\hline 8.034 & 19 & 49.64 & 402.87 & 141.81 & 3897.93 \\
\hline 8.399 & 20 & 49.70 & 402.80 & 141.99 & 3897.31 \\
\hline 8.581 & 21 & 49.78 & 402.73 & 142.20 & 3896.58 \\
\hline 8.946 & 22 & 59.66 & 392.85 & 170.43 & 3800.98 \\
\hline 9.311 & 23 & 65.09 & 387.41 & 185.96 & 3748.39 \\
\hline 9.677 & 24 & 68.46 & 386.54 & 195.59 & 3739.99 \\
\hline 10.042 & 25 & 69.73 & 382.77 & 199.21 & 3703.51 \\
\hline 10.407 & 26 & 70.62 & 381.88 & 201.77 & 3694.86 \\
\hline 10.772 & 27 & 71.11 & 381.39 & 203.15 & 3690.17 \\
\hline 11.138 & 28 & 71.77 & 383.23 & 205.03 & 3707.99 \\
\hline 11.503 & 29 & 71.52 & 380.99 & 204.32 & 3686.23 \\
\hline 11.868 & 30 & 71.59 & 380.91 & 204.54 & 3685.48 \\
\hline 12.234 & 31 & 72.03 & 382.97 & 205.79 & 3705.44 \\
\hline
\end{tabular}

Tab. 5 and Figs. 11 and 12 show variations in gas inventory composition and energy balance during the storage of natural gas and hydrogen mixture. According to simulation results and depending on natural gas and hydrogen injection scenarios, simultaneously with natural gas injection, it is possible to store between 80-205 gigawatt hours $(\mathrm{GW} \cdot \mathrm{h})$ of energy in the hydrogen form. As predicted, by increasing hydrogen content in gas storage inventory, the energy value of the stored gas mixture is decreasing. A reason for this is the lower calorific value of hydrogen per unit of volume, compared to natural gas. If the only hydrogen is stored in the reservoir (compared to natural gas), the working gas volume of UGS Alfa should be increased 3.5 times, to store the same amount of energy. 
a)

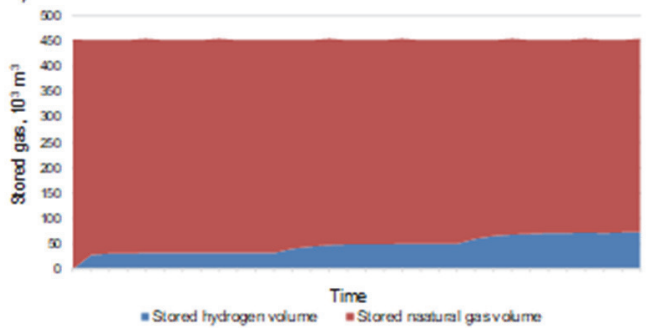

b)

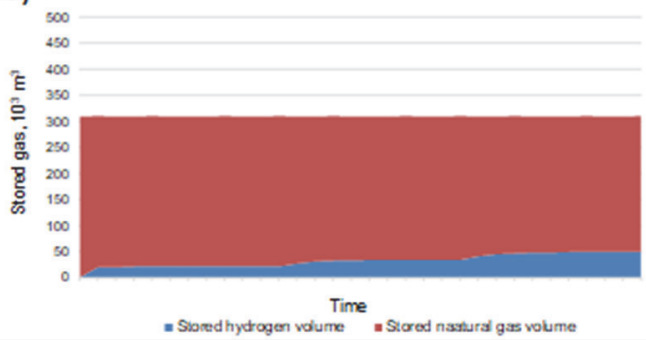

c)

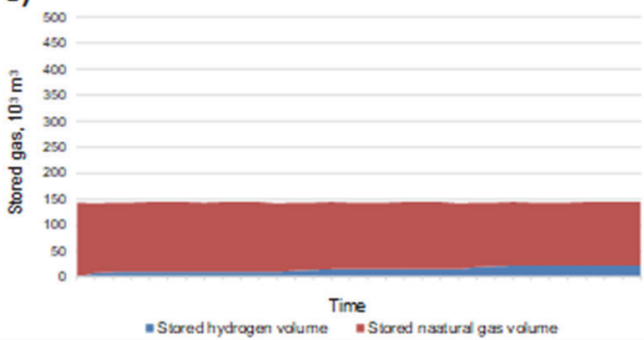

Figure 11 Stored natural gas and hydrogen inventory over time: a) in UGS Alfa; b) in Alfa 1 ; c) in Alfa 2

a)

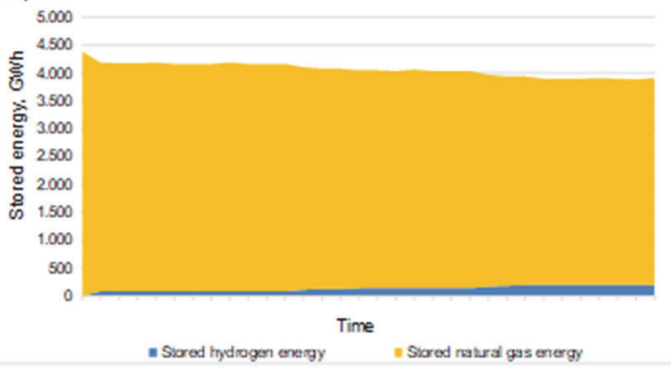

b)

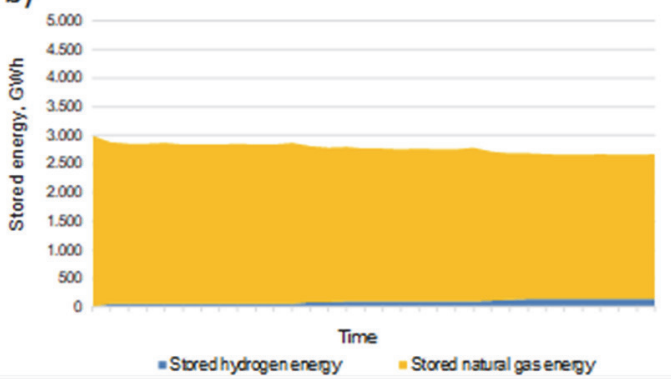

c)

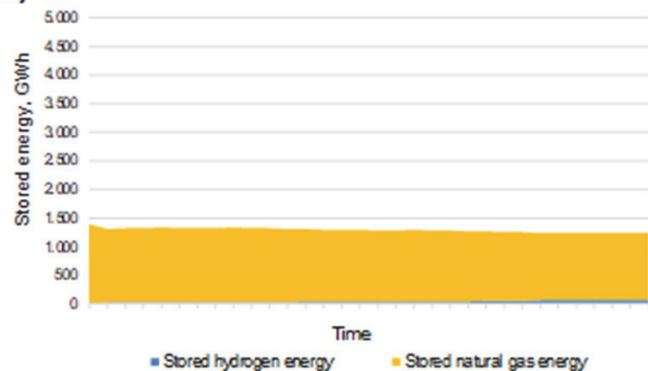

Figure 12 Stored energy balance over time: a) in UGS Alfa; b) in Alfa 1 ; c) in Alfa 2
For all simulation scenarios regarding natural gas and hydrogen mixture injection, the physical properties of the gas mixture do not meet the quality specified in the standard gas quality prescribed by the General Conditions of Gas Supply in the Republic of Croatia [24] (in terms of composition, density, and heating value).

\section{NECESSARY CHANGES OF THE ENERGY REGULATORY FRAMEWORK}

At present time, the total volume of underground gas storage in EU countries amounts to $1130 \mathrm{TW} \cdot \mathrm{h}$. Over the past several years, the total working volume of underground gas storage has decreased by $4 \%$. This downward trend in the underground gas storage volume is quite indicative if we consider the question of the decarbonisation process, which is the cornerstone of the EU energy policy. The reduced capacity of underground gas storage gives negative cross-sectoral (gas/electricity) effects. The European Gas Infrastructure Association, Gas Infrastructure Europe - GIE, recently published a study with ARTELYS, whose preliminary results were presented at the $32^{\text {nd }}$ Madrid Forum. The study analyses the ability of the electricity system to meet the demand while reducing gas storage capacity at the EU level. This made it possible to assess the value of storage capacities of European gas storage facilities for the first time.

In this analysis, based on the assumptions of common scenarios with the European Network Transmission System Operators - ENTSO, it was concluded that in 2030, operating costs for electricity generation and distribution would increase by one billion euro a year, resulting in the reduction of gas storage capacity by approx. $10 \%$. Given the necessary changes in the regulatory framework for the gas and electricity sectors, it is the opinion of the authors of this paper that significant upgrades in the regulatory part are not necessary. The changes will be needed regarding the administrative and legal requirements that these energy entities should fulfil. The existing legal and regulatory framework has been established without considering new technologies, for example Power to Gas technology, as well as increasing the level of hydrogen in the mix with natural gas. It is, therefore, necessary to adjust the current legal framework and fiscal regime [25] needed to achieve an increase in the share of renewable energy in the gas sector and to harmonize grid planning for gas and electricity gradually. Economic efficiency or market law should best serve as a factor in new sectoral cohesion. Still, it will also be necessary to provide certain minimum conditions to establish an adequate regulatory base point to ensure a certain level of equity in the new sectoral cohesion. The allowed hydrogen concentration in the EU gas network varies considerably among the Member States (from $0.1 \%$ to $10 \%$ ). There are also the EU Member States in which hydrogen injection into the gas network is not even allowed.

Fig. 13 shows the maximum percentages of hydrogen in the gas transport network in certain EU countries.

Above mentioned regulatory mismatch within the EU gas sector should be the first necessary step towards the cohesion in the regulatory area of the gas sector, not to jeopardize the further development or cohesion of the electricity and gas markets. Some progress has been made 
regarding the above-mentioned issue on the EU level, especially when applying for grants regarding Projects of Common Interest (PCI).

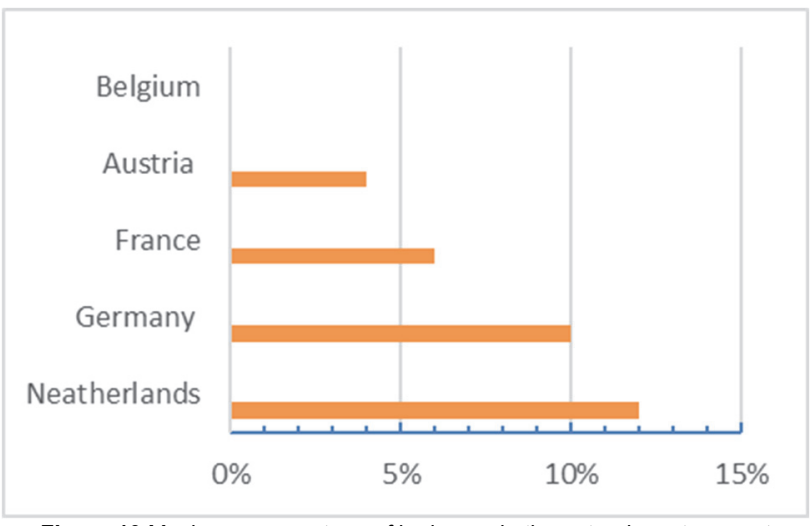

Figure 13 Maximum percentage of hydrogen in the natural gas transport network in certain EU countries [26]

To put things in breather perspective, ENTSOG has been collecting additional information about whether gas infrastructure projects competing to be put on the PCI list collected for TYNDP 2020 can already accept some level of hydrogen and if not, what are the obstacles. The additional information required by ENTSOG can be put in to 3 major groups [27]:

- $\quad$ can the project already admit blending of hydrogen?

- if not, what are the investments and related costs that would be required to ensure a certain percentage,

- what are the current barriers (legal, economic, or something else)?

ACER, as a factor of regulatory cohesion at the EU level, will have to be the principal driver of the initiative as regards sectoral cohesion; the greatest challenges will be posed to the regulators of the Member States. Also, regarding the needed adjustments to the regulatory framework, the Republic of Croatia will have to create a detailed analysis of its strategic energy goals. This would imply gradual adjustments of future regulations concerning all in compliance with the degree of the Croatian energy market development. As an EU Member State, considering necessary future changes in the regulatory framework, Croatia will have to make further investments in underground gas storage facilities and accelerate its efforts to further develop its gas network to be ready to become an infrastructure hub of a new energy era in which hydrogen is increasingly likely to have a dominant role in Europe's gas infrastructure.

\section{CONCLUSION}

The intermittent nature of most renewable energy sources presents difficulties in balancing supply and demand, causing technical problems related to running the electricity grid, and generating costs in coordinating the operation of the electricity system, [28].

Energy/underground gas storage can play a crucial role in addressing these issues since it enables the stability of the grid system to be exposed to high penetration of intermittent RES. The results of the modelling of hydrogen storage in the UGS Alfa show that, in parallel with the process of natural gas storage, $90-205 \mathrm{GW} \cdot \mathrm{h}$ of energy can be stored in a chemical form. Given the lower energy value of hydrogen (per unit of volume) relative to natural gas, an increase of hydrogen content in the gas inventory decreases the energy value of the inventory. If only hydrogen is stored in the UGS Alfa, it should be expanded approximately 3.5 times to store the same amount of energy. This indicates the need to upgrade the existing storage facilities if hydrogen completely replaces natural gas in the future. Not in all hydrogen storage scenarios, the mixture of natural gas and withdrawn hydrogen meets the current standard gas quality specified in the General Conditions of Gas Supply in the Republic of Croatia. In the opinion of the authors, the stated challenges of hydrogen production and storage should not be discouraging. On the contrary, they should be an incentive for deliberate planning of the necessary actions for the transition to new energy. These challenges are largely influenced by the fact that, at present, there is no legislative framework that would successfully address the integration of RES, natural gas storage, and transportation systems.

There are important technical, economic, regulatory and, certainly, geostrategic-energy policy obstacles (for example, attempts to decarbonize gas by mixing it with hydrogen poses a risk to current gas supply contracts, which state the gross calorific value and permitted impurity ranges; "natural gas quality clause" may even lead to penalties from customers and cause the transmission system operators to reject some or all gas); therefore, removing these legal and technical barriers will also require a significant degree of cross-border cooperation (on the EU level) to achieve the maximum utilization of the available renewable energy potential. In conclusion, the authors believe that it would be efficient to consider introducing an energy storage incentive system, which could be of interest to all participants in the development of the electricity system and would undoubtedly allow for greater integration and penetration of RES into the existing electricity system.

The constant advancement of technical and technological solutions related to energy storage approximates the profitability margin of these projects. For this purpose, it is necessary to intensively research and develop energy storage solutions to achieve the set goals defined in the Paris Agreement. Regarding the above mentioned, the authors believe that much more R\&D is needed to develop new technologies indispensable to combat climate change, with the primary responsibility for energy investments resting on governments and their decisions focused on the sustainability of the energy system (the global investment in the energy sector in 2018 was about $\$ 1.85$ trillion), [28].

\section{REFERENCES}

[1] Pavlović, D., Banovac, E., \& Vištica, N. (2018). Defining a composite index for measuring natural gas supply security The Croatian gas market case. Energy policy, 114(2018), 3038. https://doi.org/10.1016/j.enpol.2017.11.029

[2] Gaurina-Međimurec, N., Novak Mavar, K., \& Majić, M. (2018). CCS technology: overview of projects, technology and monitoring. Rudarsko-geološko-Naftni Zbornik, 33(2), 1-15. https://doi.org/10.17794/rgn\%20zbornik.v33i2.5491

[3] See https://ec.europa.eu/clima/policies/strategies/2050 
[4] Gaurina-Međimurec, N., \& Novak Mavar, K. (2017). Depleted hydrocarbon reservoirs and $\mathrm{CO} 2$ injection wells $\mathrm{CO}_{2}$ leakage assessment. Rudarsko-geološko Naftni Zbornik, 32(2), 15-27. https://doi.org/10.17794/rgn.2017.2.3

[5] Foh, S., Novil, M., Rockar, P., \& Randolph, P. (1979). Underground hydrogen storage. Final report, Institute of Gas Technology, Chicago, 268.

[6] See https://hydrogeneurope.eu

[7] Carden, P. O. \& Paterson, L. (1979). Physical, chemical, and energy aspects of underground hydrogen storage. International Journal of Hydrogen Energy, 4(6), 559-569. https://doi.org/10.1016/0360-3199(79)90083-1

[8] Panfilov, M. (2016.). Underground and pipeline hydrogen storage. Compendium of Hydrogen Energy, 2, 91-115. https://doi.org/10.1016/B978-1-78242-362-1.00004-3

[9] Davison, J., Arienti, S., Cotone, P., \& Mansuco, L. (2009). Co-production of hydrogen and electricity with $\mathrm{CO} 2$ capture. Energy Procedia, 1(9), 4063-4070. https://doi.org/10.1016/j.egypro.2009.02.213

[10] Wolf, T. P. \& Bauer, S. (2015). Subsurface porous media hydrogen storage - scenario development and simulation. Energy Procedia, 76(2015), 565-572. https://doi.org/10.1016/j.egypro.2015.07.872

[11] Gupta, R., Basile, A., \& Veziroğlu, T. (2015). Compendium of hydrogen energy. Woodhead Publishing Series. Retrieved from https://www.elsevier.com/books/compendium-ofhydrogen-energy/gupta/978-1-78242-362-1

[12] See https://gie.eu.com

[13] Tek, M. R. (1996). Natural Gas Underground Storage. PennWell Books, Tulsa, USA.

[14] Bauk, A. (2003). Podzemno skladištenje plina. INA Industrija nafte d.d., Naftaplin, Zagreb. (in Croatian)

[15] Onderka, V., Vancura, P., \& Wolf, I. (1994). Carbon Isotope study of methane production in a town gas storage reservoir. Fuel, 73(5), 747-752. https://doi.org/10.1016/0016-2361(94)90019-1

[16] Assaf, J. \& Shabani, B. (2016). Transient simulation modelling and energy of a standalone solar-hydrogen combined heat and power system integrated with solar thermal collectors. Appl. Energy, 178(2016), 66-77. https://doi.org/10.1016/j.apenergy.2016.06.027

[17] Assaf, J. \& Shabani, B. (2018). Experimental study of a novel hybrid solar-thermal/PV- hydrogen system: Towards $100 \%$ renewable heat and power supply to standalone applications. Energy, 157(2018), 862-876. https://doi.org/10.1016/j.energy.2018.05.125

[18] Garca-Valverde, C., Miguel, R., \& Martínez-Béjar, A. Urbina (2008). Optimized photovoltaic generator-water electrolyser coupling through a controlled DC-DC converter. International Journal of Hydrogen Energy, 33(2008), 5362. https://doi.org/10.1016/j.ijhydene.2008.06.015

[19] See https://www.siemens.com

[20] Bulatov, G. G. (1979). Underground storage of hydrogen. $\mathrm{PhD}$ Thesis. Moscow Gubkin Oil and Gas University Buzek,

[21] See https://www.underground-sun-storage.at

[22] Analize i podloge za izradu energetske strategije Republike Hrvatske. Energetski Institut Hrvoje Požar, Zagreb, 2018.

[23] See https://narodnenovine.nn.hr/clanci/sluzbeni/2020_03 25 602.html (in Croatian)

[24] See https://narodnenovine.nn.hr/clanci/sluzbeni/2018_06 50_1003.html (in Croatian)

[25] Karasalihović Sedlar, D., Barbir, G., \& Brkić, V. (2016). Types of fiscal regime in hydrocarbon exploration and production. Rudarsko-geološko-Naftni Zbornik, 32(1), 4554. https://doi.org/10.17794/rgn.2017.1.6

[26] See https://www.iea.org/reports/world-energy-investment2018

[27] See https://www.entsos-tyndp2020-scenarios.eu/

[28] Pavlović, D., Bolanča, A., \& Šijanović Pavlović, S. (2018). Internet of Things $\mathrm{i}$ Blockchain kao temelj sigurnosti energetskih sustava s visokim udjelom intermitentnih izvora.

11th International Scientific and Professional Conference

"Crisis Management Days 2018", 393-409. (in Croatian)

\section{Contact information:}

Ivan ZELENIKA, PhD

Gas Storage System Operator (PSP L.T.D.),

Veslačka 2-4, 10000 Zagreb, Hrvatska

E-mail: ivan.zelenika@psp.hr

Darko PAVLOVIĆ, Asst. Prof., PhD

(Corresponding author)

Gas Transmission System Operator (PLINACRO L.T.D.),

Savska cesta 88a, 10000 Zagreb, Hrvatska

E-mail: darko.pavlovic@plinacro.hr

Pavo RAJIČ, Mag. Ing. Petrol

Gas Storage System Operator (PSP L.T.D.)

Veslačka 2-4, 10000 Zagreb, Hrvatska

E-mail: pavo.rajic@psp.hr

Tomislav KOVAČIĆ, LL. B.

Gas Storage System Operator (PSP L.T.D.)

Veslačka 2-4, 10000 Zagreb, Hrvatska

E-mail: tomislav.kovacic@psp.hr

Melita SRPAK, univ. spec. oec., mag. agr.

Varaždin County, Institute for Physical Planning,

Mali Plac 1a, 42000 Varaždin, Hrvatska

E-mail: melita.srpak@gmail.com 